\title{
The Role of the German State in the Emerging Biogas Industry ----Lessons for China
}

\author{
Suning Jin, Jingwei $\mathrm{Xu}^{*}$
}

\author{
University of Shanghai for Science and Technology, P.R.China \\ *Corresponding author. Email: jingwei.xu@hotmail.com
}

\begin{abstract}
Germany is an undisputed leader in promoting biogas industry und biogas utilization in the country, using advanced policies. It has gone through 30 years of development in this sector, since the German state first introduced the Electricity Feed-in Act in 1991. This article focuses on the role of the German State in the emerging biogas industry during the period from 1990 to 2009, from which rapid growth of biogas plants and system dynamics in the emerging biogas industry could be observed. The German success also indicates how state intervention could stimulate positive interactions between system functions, leading to a virtuous cycle. As Chinese government also takes actions in accelerating the growth of modern high-efficient bio-energy sector in order to achieve the ambitious goals, strategies to stimulate the development of biogas sector are suggested for Chinese government, based on learning lessons from German state.
\end{abstract}

Keywords: German biogas industry, policies and regulations, renewables-based electricity generation, system functions.

\section{INTRODUCTION}

Thanks to Chinese government's immense investment and passage of new renewable energy regulations in 2006 and release of its amendments in 2017, bioenergy in China has been developing at a rapid pace, with installed biomass power generation capacity increased sharply from $1.4 \mathrm{GW}$ in 2006 (Fernandez, 2021) to $25.2 \mathrm{GW}$ in 2020 (Liu, 2021). However, the biogas industry of China is still in the arising phase, as installed capacity of biomass power generation on average is low. Experts (Xu et al., 2018) indicated that the development of biogas plants in China mainly relies on subsidies from municipal, provincial as well as central government, challenged with lack of systemic policy instruments and technological innovation, inadequate equipment R\&D and incomplete management system.

In 2020, ten ministries and commissions in China including the National Development and Reform Commission, the National Energy Administration and the Ministry of Agriculture and Rural Affairs jointly issued the "Guiding Opinions on Promoting the Industrialization of Biogas". This suggests the growing importance of biogas industry for China and governments' determination to incorporate biogas sector into the national energy system.

With the notion of "Energiewende"(energy transition), Germany was the first country attempt to transform a centralized fossil-based energy system into a decentralized renewable-based system, using advanced policies involving innovative technologies. With a share of 23.6 percent of the total renewable electricity generation and a $13.0 \%$ share of biogas/biomethane in renewables-based electricity generation (Winquist et al., 2021), bioenergy has become one of the pillars of the German energy transition. In Germany, biogas is mainly utilized for heat and electricity production (CHP), while a small share of biogas plants upgrade biogas to biomethane and inject it to state gas grid. By the end of 2019, there are 9527 biogas installations and installed electricity capacity is $5000 \mathrm{MW}$, providing 9.5 million German households with biogas-based electricity. (German biogas association, 2020) Supported by various policies and regulations issued by the federal government and influenced by institutional changes in the last three decades, the German biogas Industry has gone through the formative stage in the 1990s, the stage of market diffusion from 2004 to2009 and the 
stage of mature market under several amendments made to renewable energy law. Currently, German biogas industry is in the decline phase due to the state's intent to make renewable power producers more market-oriented. This article will only focus on the time period between 1990 and 2009 in order to explore the role of German State in an emerging technological field in a transition from a formative stage of emergence to a stage of market diffusion. Meanwhile, the dynamics which underlie the build-up processes "where policy makers may need to intervene, not necessarily the set-up of the structural components (actors, networks, institutions) (Bergek et al., 2008)" are the main focus.

\section{THE PIONEERING STAGE OF GERMAN BIOGAS INDUSTRY}

The increasing public discourse on climate protection in the early 1990s became an important context for the remuneration for electricity from renewable sources. German biogas industry began to take shape in 1991 when the government introduced the Electricity Feed-in Act, which obliged, for the first time, grid operators to feed in electricity produced from renewable energy sources such as biogas. Most importantly, this act states that producers of renewable energy are compensated for higher production costs compared to conventional electricity (94), more specifically, for the specified payment rate of $75 \%$ of the customers 'electricity tariff (around 14pfennings/kWh ). This helped to set up expectation among engineers and entrepreneurs, convincing them that biogas could become a promising sector for electricity production. In spite of this, farmers accepted this trend very conditionally, since the biogas plants did not work in a profitable way due to the high costs of construction.

It was only with the increased tariff rates specified in the Electricity Feed-in Act amendment of 1994 (around 15pfennings/kWh) that an appreciable expansion of plant construction finally took place. Other than that, knowledge about new kinds of substrates for biogas production was acquired through scientific research as well as in practical applications: the co-fermentation of other organic wastes, such as vegetative raw material, could multiply the gas yield several times compared to the digestion of pure semiliquid manure. This progress was quite promising for co-fermentation plant operators, as they could receive money, e.g. from food producers, for accepting and dealing with organic residues, in addition to the feedin tariff. In response to this biogas trend, the German Biogas Association was established in 1992 as a trade forum of primarily small and medium-sized agricultural operators and businesses, which provided the sector with biogas technology and process engineering.

From the mid-1990s onward, business founders who enjoyed higher education in technology and had an agricultural background had also turned to biogas technology. By gaining their practical experience through implementing their ideas for plants in their own experiments, mostly on their parents' farms, these entrepreneurs became recognized in local networks and were able to win the trust of farmers, offering comprehensive advisory services for potential operators. Although the manufacturers for CHP (Combined Heat and Power engines) and agricultural technology did not gain a foothold at this point, they reacted to the requirements of the plant's builder and adapted components accordingly. At this point, biogas plants were primarily constructed on a farm-scale, using the farm's own waste for biogas and electricity production.

A larger capacity was achieved in the demonstration plants funded by the Federal Research Ministry (1991-1998). With the aim to explore the environmentally friendly disposal of residues and waste materials, large-scale biogas plants were implemented with the capacity range of $300-500 \mathrm{Kw}$ el. These projects demonstrated the possibility to generate biogas on a large scale and to increase the profitability by the co-digestion of biological waste and other solid materials. Thanks to these demonstration programs, the advantage of cofermentation spread quickly among plant operators. However, as a result of competition with commercial organic waste digestion plants, the demand for the service of organic waste disposal decreased. By the end of the 1990s, organic waste had become a scarce commodity, which means that "economic viability of agricultural organic waste co-digestion plants dropped drastically" (Brüns et al., 2011). This leads to the urgency to exploit the energy crops, which were not yet accepted by the compensation system during this period. Meanwhile, the distinct drop in conventional electricity prices (a reduction of around 1 pfenining $/ \mathrm{kWh}$ ), as a result of the liberalization of the electricity market in 1998/1999, weakened the competitiveness of electricity generated from biogas.

\section{THE BOOM-UP OF BIOGAS INDUSTRY}

The government soon realized that liberalization of the energy market did not help to increase the share of renewable energy, as renewable energy sources were 
still more expensive. Therefore, the Electricity Feedin Act was replaced with one of the most important regulations - the Renewable Energy Sources Act in 2000. Under this new act, feed-in prices are no longer linked to electricity retail prices, but fixed for 20 years from the start of operation of each new qualifying plant. This law is also the major driving policy behind the rapid expansion of biogas production in Germany.

In 2001, the „Ordinance on generation of electricity from biomass ${ }^{\text {"e }}$,Biomass ordinance $\left.{ }^{\prime \prime}\right)$ was published by the state defining which substances fall under biomass, which technologies should be used for the conversion of biomass to electricity, and which environmental standards need to be observed. By setting regulations with regard to an environmentally friendly utilization of biomass, the state guided the search to help to secure the aims and intentions of the Renewable Energy Sources Act and improved the legitimacy of biogas sector in the public in the long term.

In 2002, in response to the EU directive for the support of renewable energy, national targets for the generation of electricity from renewable sources were set in the Federal Government's sustainability strategy. This strategy formed a discourse that empowered the political actors to establish more extensive incentives in order to realize the potential of biomass.

In 2004, the development of biogas sector was significantly stimulated by the amendment made to the Renewable Energy Sources Act. During the preparations for the amendment of the Act, all interested parties, such as the German Farmers Union and the Federal Bioenergy Union, were given the opportunity to influence the 2004 amendment. As a result, economic incentives were raised in the act of 2004 by establishing the bonus system, which consisted of a renewable resources bonus, a technology bonus and a CHP bonus. Under this act, the biogas sector became far more lucrative than before, as biogas plant operators had the chance to receive almost twice as much as before. This resulted in an extraordinary boom for the German biogas sector. In addition to the growth of farm-based biogas plants with lower range in terms of capacity, larger, industrial biogas plants also experienced a rapid growth since 2004. These plants were operated by joint operating companies or so-called energy service providers, suggesting that biogas generation became a lucrative opportunity for business investors. Since 2004, there was a substantial change in the nature of the operators, as the largest proportion of biogas plants was run by cooperatives and private companies, while the agricultural biogas plants with individual operators were in the minority. (Brüns et al., 2011)

There were some setbacks between 2007 and 2008 , as the biogas industry was on the one hand disturbed by the controversial discussion about the competitive situation of food and energy production, on the other hand, the sector faces the problem of availability of cheap energy crops. Once again, the state played a pivotal role to compensate for the increased costs of raw materials, making changes to the tariff, such as the increase in basic tariff, increase of the bonus for CHP and technology and a new bonus was granted in the class of plants with capacity up to $500 \mathrm{kw}$.

Additionally, the new amendments encouraged biogas plant operators to make more use of slurry from farm by introducing slurry bonus for biogas plants with a capacity lower than $500 \mathrm{~kW}$. By providing plant operators with motives to increase the use of traditional agricultural residues as digester substrate, this bonus is intended to limit the use of maize feedstock in installations and to reduce the land competition to some extent. At the end of 2009, as a result of lucrative modifications made in the act, the expectations were once again fulfilled with setting up of another 1093 plants within one year.

\section{THE ROLE OF THE STATE AND DYNAMIC PROCESSES}

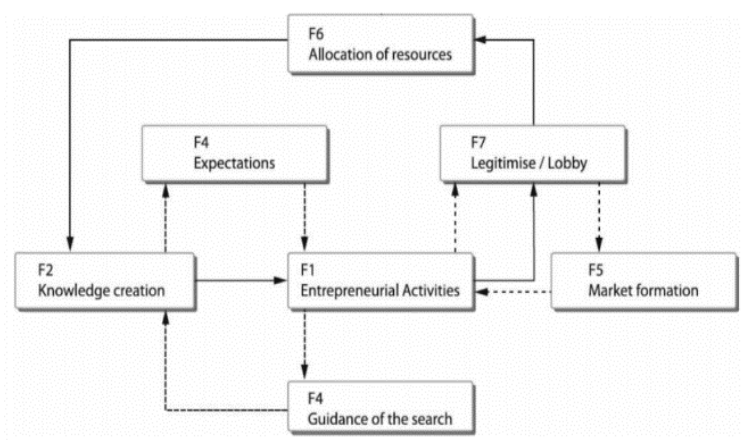

Figure 1. Overview of two possible reinforcing cycles within an Innovation System

(Source: Negro and Hekkert, Explaining the success, pp. 469)

The German biogas market is highly influenced by the regulation of the federal government. The legislative framework established by the state is the major driving policy behind the rapid expansion of biogas production in Germany, as the act makes it economically attractive for biogas production for a period over 20 years. However, it is the dynamics 
between different institutions and actors that leads to the emergence of a new technology system. Most importantly, German government played the role of a system builder very well, starting with guidance of the search. In this early stage, societal problems are identified and government goals are set to limit environmental damage. These goals legitimize the mobilization of resources to finance $R \& D$ projects in search of solutions, which, in turn, leads to knowledge development and increased expectations about technological options. (Figure 1) The private actors, such as entrepreneurs, farmers and engineers, after they begin to engage themselves in the emerging biogas sector, performed complementary activities, such as lobbying for better economic conditions and for market formation. This, in turn, sends a clear message about the market condition to the decision makers of the government. Accordingly, governments align its activities to the sector's needs so as to increase the diffusion of the technology. (Negro and Hekkert, 2008)

In this way, a communication channel between practitioners and policy makers as well as the interaction dynamics between the various system functions are established, contributing to a virtuous cycle (Figure 1) for biogas industry to mature. For example, in the post 2000 period, the availability of organic waste and public environmental concerns became two major challenges for the growth of biogas industry. Hence, as a response to the needs of private actors and to public concern, an innovative measure of bonus systems was included by the state in the 2004 amendment in order to recreate the legitimacy for biogas sector. The bonus system, on the one hand, serves the function of knowledge diffusion, as it indicates what kind of technology style and what kind of substrates are preferred in terms of efficiency of biogas plants. On the other hand, it guides the search by providing plant operators with economic incentives to follow the standardized technological settings. Such dynamics between market and policy interventions are indispensable for an emerging renewable energy industry.

\section{LESSONS FOR CHINA}

In the last year, China announced to have $\mathrm{CO} 2$ emissions peak before 2030 and achieve carbon neutrality before 2060. This also makes waste-derived biogas industry far more important for China than ever, as it helps to curb carbon emissions. In addition to that, biogas industry is meaningful in several ways, for example, in helping reduce the country's reliance on fossil fuels, diversify its energy source. Especially for rural areas, it helps, on the one hand, to reduce environmental pollution, such as open field burning of straw and agricultural residues, water pollution. On the other hand, organic fertilizer made from the slurry of the biogas plants could help to increase the farmers' income enormously. Ultimately, the biogas industry could serve the function of promoting a circular economy in China. Despite state's heavy subsidy for the construction of biogas plants in the last 2 decades, challenges like lack of successful business models, high production costs and low profit returns, insufficient productivity are listed by experts as well as practitioners in China. Hence, the successful experience of German federal government of stimulating the biogas industry can shed some light on the further development of Chinese biogas sector in the future.

First of all, from the perspective of system functions, the Chinese government should shift the role of an investor and a regulator to a role of a system builder in the biogas sector. With state and local government guiding the search in the form of policy targets, outcomes of technical or economic studies, entrepreneurs will be attracted to enter into the field to perform the innovative commercial experiments, see and exploit business opportunities. In the meantime, the two key functions (Figure 1) of allocation of resource and market formation could be followed. With the government continuously offering economic incentives, more relevant stakeholders, such as local farmers, entrepreneurs, engineers on the one hand, local municipalities, car companies, waste water companies on the other hand, are going to engage themselves in the emerging biogas sector. They should be motivated to serve the complementary functions, such as knowledge development and diffusion. And they should also be encouraged to build up alliances so that they could lobby for better resource and economic conditions for market formation and technology development and most importantly, to convey a clear message about the real market's needs to the government timely. As the development of German biogas industry shows, timely state intervention in the form of regulation is very important for the further development and virtuous circulations (Figure 1) in the emergent industry.

On the other hand, the Chinese central government should take an active role in establishing interaction channels with industry while making laws, regulations and amendments with regard to biogas development, so that they could respond to the rising problems of an emerging biogas industry more effectively. Municipalities should also be encouraged to act as the intermediate agency between central government and 
local entrepreneurs, creating more favourable local conditions for entrepreneurial activities and exploring the needs of the industry.

Secondly, rather than heavily financing the construction of biogas plants, policy instruments should be initiated to ensure a fair market for renewable energy in the long term, such as setup of a very favorable price for green electricity generated by biogas plants for a long period, such as the feed-in prices fixed for 20 years in the case of German biogas industry. Lack of consistent and effective government guidance could result in reduced incentives for entrepreneurs to initiate business projects. This, in turn, leads to the absence of a market and a low legitimacy of the biogas industry.

In addition to favourable prices for power generation, the state could artificially create the demand on the end-products or biogas-related products, such as heating, electricity from biogas obtained from slurry as well as renewable raw materials and agricultural residues, upgraded biogas, so that various actors would be incentivized to make investment in this new field, gradually leading to market formation. In this way, the emerging biogas industry will not depend solely on national subsidy framework. Instead, social and private investment into the biogas industry would be encouraged and efficiently mobilized.

\section{CONCLUSION}

This article studies the role of the German State in the emerging biogas industry during the period from 1990 to 2009 and discusses the implication for the biogas industry in China. A comparative case study method is used in this study. The German success indicates how state intervention could stimulate positive interactions between system functions, leading to a virtuous cycle. As Chinese government also takes actions in accelerating the growth of modern high-efficient bio-energy sector in order to achieve the ambitious goals, a few strategies to stimulate the development of biogas sector are suggested for Chinese government.

\section{REFERENCES}

[1] Brüns, E., Ohlhorst, D., Wenzel, B and Köppel, J. (2011) Renewable Energies in Germany's Electricity Market - A Biography of the
Innovation Process, Dordrecht, Netherland: Springer

[2] Bergek, A., Jacobsson, S., Carlsson, B., Lindmark, S. and Rickne, A., (2008) "Analyzing the functional dynamics of technological innovation systems: A scheme of analysis", Research Policy, vol.37, no.3, pp.407-429.

[3] Fernandez, Miriam (2021) Biomass Energy in China [Online], Available: http://www.bioenergyconsult.com/biomassenergy-china/ [28 May 2021].

[4] German Biogas Association (2020) Biogas market data in Germany 2019/2020 [Online], Available:

https://www.biogas.org/edcom/webfvb.nsf/id/E N-German-biogas-market-data [28 May 2021].

[5] Liu, Y.K. (2021) Biomass energy to provide heat, fuel [Online], Available: http://www.chinadaily.com.cn/a/202104/15/WS 60779480a31024ad0bab5a24_2.html [28 May 2021].

[6] Negro, S. and Hekkert, M. (2008) "Explaining the Success of Emerging Technologies by Innovation System Functioning: The Case of Biomass Digestion in Germany", Technology Analysis \& Strategic Management, vol.20, no.4, pp. 465-482.

[7] Winquist, E.; Van Galen, M.; Zielonka, S.; Rikkonen, P.; Oudendag, D.; Zhou, L. and Greijdanus, A. (2021) Expert Views on the Future Development of Biogas Business Branch in Germany, The Netherlands, and Finland Until 2030, Sustainability, vol.13, no.3, pp. 1148.

[8] Xu, H., Han, Z.Y., Wu J., Shi, G.Z. (2018) [Comparative Analysis on the Development Process of China-Germany biogas project] China Biogas, vol.36, no.4, pp. 101-108 